\title{
Exploring the effects of learning style on the use of an Electronic Library System
}

\author{
JOANNA WORTH and CHRISTINE FIDLER \\ Division of Learning Development/School of Computing and Mathematics \\ De Montfort University
}

\section{Introduction}

Electronic information retrieval is becoming an increasing trend (most notably in higher education) due to its cost effectiveness and ability to manage large quantities of information. As large differences in the user population often give rise to differing requirements between users of information retrieval systems, an insight into individual searching behaviour is important. This has been widely recognised by writers such as Shniederman (1986) and Thimbleby (1990).

The electronic library will be significant in changing the role of educational libraries. Research into individual differences and search behaviour within the electronic library environment is essential if Electronic Library Systems (ELS) are to work effectively. Sources of individual difference include age, gender, subject knowledge, personality and learning style.

An ELS can be defined as :

"A system designed for the provision and management of information for the purposes of teaching, learning and research in which the full-text of materials is held in electronic form. Its adaptability and cost-effectiveness allows the needs of individual institutions to be to met effectively."

The primary aim of the research reported here is to assess the ability of ELINOR, an example ELS, to facilitate the information retrieval activities of different user groups when classified by learning style. ELINOR is an acronym for Electronic Library INformation Online Retrieval. The ELINOR system comprises an image and text database of books, journals and course materials which can be directly accessed by students and staff via desktop workstations distributed across the various campuses of De Montfort University.

\section{Rationale for the research}

The authors have not found any research regarding the effects of individual differences on information retrieval within the electronic library environment. Previous research has attempted to correlate user characteristics with searcher behaviour in relation to other forms of electronic information retrieval (Allen, 1991; Balaraman, 1991; Bellardo, 1985; Borgman, 1989; Ford and Ford, 1993; Logan, 1990 ; Palmer, 1991; Saracevic et al., 1988). However, these studies provide little of substance upon which to build research within the electronic library field.

The majority of empirical research also demonstrates that the information retrieval behaviour of different user groups has typically been measured in terms of performance, defined as outcome (for example, precision and recall). However, the present research focuses on the process or patterns of retrieval associated with user groups with differing learning styles when performing a range of tasks. The major concern of the research is therefore with the actions performed rather than the outcome achieved. Studies which have similarly sought to identify search processes include those of Ellis, Ford and Wood (1993) and Liu and Reed (1994). However, both these studies were 
conducted within a hypertext or hypermedia environment. Logan (1990) found a relationship to exist between learning style and search styles. Although the actual patterns of search behaviour were not considered, search styles being different from patterns, the results presented by Logan suggest that research regarding the influence of learning style on information retrieval patterns requires further examination.

\section{Research methodology}

The research methodology employed within this investigation includes both quantitative and qualitative methods of inquiry. The decision to reject a strict statistical approach was made with reference to the work of Fitzgerald et al. (1985). Fitzgerald et al. suggest that information systems and their relationship to society is closely related to human activities and involves the study of experiences, attitudes, values, effects and responses. A purely scientific approach to the investigation of these relationships is therefore inappropriate. This is a view with which Hirshcheim (1985) also agrees. Galliers and Land (1987) explain that the focus of study in information systems research must include behavioural considerations, including assessment of the effectiveness of systems within their operational setting and the impact of systems on individuals. They propose a taxonomy of approaches to information systems research including methods which place an emphasis on the individual. The research methodology is in agreement with their recommendations. The methodology also contains elements of research methodologies previously employed within the field of individual differences and information retrieval behaviour.

The target population for the research comprises students undertaking courses within the School of Computing and Maths at De Montfort University. In order to identify the learning styles of the target population students were asked to complete the Learning Styles Questionnaire (LSQ) (Honey and Mumford, 1992). The LSQ presents a suitable method of measurement being reliable, valid and well-known and having been widely used in management training (Rae, 1986; Keal, 1988). It is quick to administer, requires no expert knowledge for interpretation and there are no restrictions on its use. It is also a self-report inventory which can be completed by large numbers of people at the same time. Measures were taken to account for the influence of any extraneous factors, such as age, gender or search experience, ensuring that the effect of learning style, alone, could be examined.

Fifty-seven students undertook training and tasks using ELINOR, lasting approximately two hours for each student. Several tasks were provided to assess ELINOR's ability to facilitate patterns of information retrieval over a range of both simple and complex activities. Training ensured familiarity with the fundamental elements of ELINOR needed to perform the tasks and was undertaken immediately prior to the tasks to avoid problems of retention.

A logging system was employed to track the progress of participants through the tasks and so ascertain the exact patterns of retrieval. Data regarding search patterns was recorded separately for each task in order to assess the process of information retrieval adopted when performing different activities. Logging systems are incapable of recording users' perceptions of their searches or reflecting users' satisfaction (Kurth, 1993), therefore participants were also asked to complete an evaluation questionnaire. This included questions regarding the students' perceptions of ELINOR and the extent to which the system allowed them to retrieve information in the way they desired. Interviews were also conducted with each student in order to gain a further insight into their attitudes towards ELINOR. 


\section{Preliminary findings}

Preliminary findings suggest that there may be some relationship between information retrieval behaviour and different learning style groups when using ELINOR to perform a range of tasks. Further statistical analysis is needed to gain a more informed picture of the overall effect, and which aspects of information retrieval patterns are more influenced than others. If further analysis supports the relationship, then the research may indicate that learning style requires consideration in the design of future ELS. In this instance the finding may assist in prescribing the functionality necessary within ELINOR (or indeed any ELS of similar description) to facilitate the patterns of information retrieval associated with each learning style over the range of tasks included within this research. This will aid in designing ELS which are more effective in meeting the requirements of target users. If little evidence of a relationship exists, the findings may suggest that learning style does not require consideration when designing ELS.

Joanna Worth

Division of Learning Development / School of Computing and Maths

De Montfort University

The Gateway

Leicester LE1 9BH

Tel : (0116) $2551551 \times 8164$

Email:jjworth@dmu.ac.uk

Christine Fidler

Department of Information Systems

School of Computing and Maths

De Montfort University

The Gateway

Leicester LE1 9BH

Tel : (0116) 2577499

Email:cf@dmu.ac.uk

\section{$\underline{\text { References }}$}

Allen, B. Topic Knowledge and Online Catalog Search Formulation. Library Quarterly, Vol 61, Issue 2, 1991.

Balarman, K. End-User Studies in CD Rom Environment - Work in Progress. Proceedings of the ASIS Annual Meeting, Vol 28, October 1991.

Bellardo, T. An Investigation of Online Searcher Traits and Their Relationship to Search Outcome. Journal of the American Society for Information Science, Vol 36, Issue 4, 1985.

Borgman, C.L. All Users of Information Retrieval Systems are not Created Equal : An Exploration into Individual Differences. Information Processing and Management, Vol 25, Issue 3, 1989.

Ellis, D., Ford, N. and Wood, F. Hypertext and learning styles. The Electronic Library, Vol 11, No 1, February 1993. 
Fitzgerald, G., Hirschheim, R.A., Mumford, E., Wood-Harper, A.T. Information Systems Research Methodology : An Introduction to the Debate. Chapter 1 in Research Methods in Information Systems, Ed. Mumford, E, Hirschheim, R, Fitzgerald, G, Wood-Harper, AT. Pub. Elsevier Science Publishers B.V., 1985.

Ford, N. and Ford, R. Towards a Cognitive Theory of Information Accessing : An Empirical Study. Information Processing and Management, Vol 29, No. 5, 1993.

Galliers, D. and Land, F. Choosing Appropriate Information Systems Research Methodologies. Communications of the ACM, Vol 30, Number 11, November 1987.

Hirschheim, R. Information Systems Epistemology : A Historical Perspective. Chapter 2 in Research Methods in Information Systems. Ed. Mumford, E, Hirschheim, R, Fitzgerald, G, WoodHarper, AT. Pub. Elsevier Science Publishers B.V., 1985.

Honey, P. and Mumford, A. The manual of learning styles. Pub. Peter Honey, 1992.

Keal, P. A New Style in Burton: Learning. ICT May/June 1988.

Kurth, M. The limits and limitations of transaction log analysis. Library Hi Tech, Issue 42 - 11 : 2, 1993.

Logan, E. Cognitive styles and online behaviour of novice searchers. Information Processing and Management, Vol 26, No. 4, 1990.

Liu, M. and Reed, W. M. The relationship between the learning strategies and learning styles in a hypermedia environment. Computers in Human Behaviour, Vol 10, No. 4, 1994.

Palmer, J. Scientists and information I : Using cluster analysis to identify information style. The Journal of Documentation, Vol 47, No. 2, June 1991.

Palmer, J. Scientists and information II : Personal factors in information behaviour. The Journal of Documentation, Vol 47, No. 3, September 1991.

Rae, L. The application of learning styles. ICT March/April 1986.

Saracevic, T., Kantor, P., Chamis, A. Y. and Trivison, D. A study of information seeking and retrieving. Journal of the American Society for Information Science, Vol 39, Issue 3, 1988. (Part I Background and methodology pp. 161 - 176. Part II Users, Questions and Effectiveness pp. 177 - 196. Part III Searchers, Searches and Overlap pp. 197 - 216).

Shneiderman, B. Designing the user interface : strategies for effective human-computer interaction. Addison-Wesley Publishing Co., 1988.

Thimbleby, H. User interface design, ACM Press Frontier Series, Addison-Wesley Publishing Company, 1990. 